\title{
Environmental analysis of gasoline blending components through their life cycle
}

\author{
T.M. Mata ${ }^{\mathrm{a}, *}$, R.L. Smith ${ }^{\mathrm{b}}$, D.M. Young ${ }^{\mathrm{b}}$, C.A.V. Costa \\ ${ }^{a}$ Laboratory of Processes Environment and Energy Engineering, Faculty of Engineering, University of Porto, Rua Dr. Roberto Frias \\ 4200-465 Porto, Portugal \\ ${ }^{\mathrm{b}}$ National Risk Management Research Laboratory, Office of Research and Development, US Environmental Protection Agency, 26 W. Martin \\ Luther King Drive, Cincinnati, $\mathrm{OH} 45268$, USA
}

\begin{abstract}
The contributions of three major gasoline blending components (reformate, alkylate and cracked gasoline) to potential environmental impacts (PEI) are assessed. This study estimates losses of the gasoline blending components due to evaporation and leaks through their life cycle, from petroleum refining to vehicle refuelling. A sensitivity analysis is performed using different weighting factors for each potential environmental impact category, in order to assess the effect of each blending component on the total potential environmental impacts. The results indicate that reformate and cracked gasoline mainly contribute to photochemical oxidation followed by aquatic toxicity, terrestrial toxicity and human toxicity by ingestion. On the other hand, alkylate contributes mostly to aquatic toxicity but very little to photochemical oxidation. From the sensitivity analysis, a high weighting on the impact categories for aquatic toxicity, terrestrial toxicity and human toxicity by ingestion leads to alkylate having the largest potential impacts of the three blending components, whereas other combinations of weighting factors indicate that alkylate has the lowest potential impacts.
\end{abstract}

(C) 2003 Elsevier Ltd. All rights reserved.

Keywords: Gasoline blending components; Reformate; Alkylate; Cracked gasoline; Potential environmental impacts

\section{Introduction}

Within the past 30 years the petroleum industry has undergone considerable changes. Plants have grown in size, complexity and connection with other plants, containing very large items of equipment. Process conditions such as pressure and temperature have become more severe. The relative amount of storage has been reduced and the response of the process is often faster. These factors have greatly increased the potential for toxic releases or the danger of serious large-scale incidents such as fire or explosion. Public environmental concern has been growing, and the adequacy of existing procedures has been subjected to an increasingly critical examination in both human and economic terms [1-3].

A refinery is an integrated group of manufacturing processes that vary in number and type according to the

\footnotetext{
* Corresponding author. Tel.: +351-225-081-687; fax: +351-225 081-449.

E-mail address: tmata@fe.up.pt (T.M. Mata).
}

variety of products produced and demanded. Petroleum refining involves many operations such as treating, separating, processing and converting of petroleum products and blending, handling, storing and shipping of the refined products [4]. Each of these refinery activities is a source of volatile organic compound (VOC) emissions, which arise as a result of leaks from process equipment, evaporation from storage tanks, handling, displacement of vapour during volume changes, loading, unloading and spillage [5]. These VOC emissions are considered to be fugitive emissions and make up a significant portion of the total refinery air emissions. Goyal [6] reports that refineries' fugitive emissions typically represent $0.8-1.2 \%$ of the total throughput. Valves are usually the single largest source of fugitive emissions. Point sources of fugitive emissions, such as single pieces of equipment, are usually small. However, cumulative emissions throughout a plant can be very large, based on the large number of equipment pieces that can leak such as valves, pumps, flanges, compressors, etc. According to Siegell [7], $86 \%$ of the VOC fugitive 
emissions in a refinery are from non-point sources. Siegell [7] also describes the source distribution of refinery VOC emissions, indicating that fugitive emissions from leaking piping systems are the largest VOC emission source, typically accounting for $40-60 \%$ of the total VOC emissions. Contributions to total VOC emissions from different source categories depend on the specific processes used and the emission controls installed. Control of fugitive emissions involves minimising leaks and spills through monitoring operating conditions and good housekeeping and maintenance. In many refineries and petrochemical plants, loss reduction programs are very successful and have provided many rewards [6,8-11].

The petroleum refining industry converts crude oil into several refined products. According to the market demand, two or more of these refined products can be combined together to generate other products (e.g. gasoline). Reformate, alkylate and cracked gasoline are common gasoline blending components, which are produced, respectively, by the processes of catalytic reforming, catalytic alkylation and fluidised catalytic cracking (FCC).

After their production reformate, alkylate and cracked gasoline (along with other minor components) are blended together to obtain gasoline with desired properties. Gasoline is stored in tanks at the refinery, and then it is transferred to tank trucks, rail cars, barges, coastal tankers, etc., using various loading techniques, i.e. top, bottom, or submerged loading. From refinery dispatch stations gasoline is delivered directly to service stations (stored in underground tanks) or to marketing depots where it is stored in tanks similar to those used in refineries. At service stations gasoline is dispensed into automobile fuel tanks. Fugitive emissions occur throughout the gasoline distribution chain [1]. Service station VOC emissions typically account for more than $50 \%$ of the emissions from the gasoline distribution chain [5]. Several sources of service stations emissions can be identified, such as, storage tanks (due to withdrawal and breathing), vehicle refuelling (due to vapour displacement and spillage when refuelling) and other fugitive emissions from pieces of equipment (e.g. pumps, valves, etc.). Considerable reductions of hydrocarbon emissions from the gasoline distribution network can be achieved by using several existing techniques or control measures [5].

In this study, the contribution of reformate, alkylate and cracked gasoline to the potential environmental impacts (PEI) were evaluated separately, i.e. assuming that the three components are not blended together over all of the life cycle stages. Keeping these evaluations separate, it is possible to assess the relative contribution of each one of the gasoline blending components to the potential environmental impacts, independent of the amount of each in a final blend. Simulations were performed for the reforming process, which is the most variable in terms of its product [12]. Losses of the gasoline blending components due to evaporation and leaks are estimated through their life cycle, from petroleum refining to vehicle refuelling. A sensitivity analysis was performed using different weighting factors for each potential environmental impact category, in order to assess the effect of each blending component on the total PEI. The potential environmental impacts were evaluated using the Waste Reduction (WAR) algorithm [13], which includes eight categories: human toxicity by ingestion and by dermal/inhalation routes, terrestrial toxicity, aquatic toxicity, photochemical oxidation, acidification, global warming and ozone depletion. This study shows which gasoline blending component contributes the most to the potential environmental impacts. With this information, a refinery could devise a blending policy that obtains the desired gasoline while minimising the potential environmental impacts.

\section{Methodology and assumptions}

The proposed methodology is based on the estimation of average emission factors for gasoline blending components (reformate, alkylate and cracked gasoline) from the refinery to vehicle filling stations and the various loading and unloading techniques. The determination of hydrocarbon emissions is based on an assumed amount of reformate, alkylate and cracked gasoline produced and distributed per year, i.e. $6 \times 10^{6} \mathrm{~m}^{3} /$ year of each component, and on the estimation of their chemical composition. Then the evaluation of the potential environmental impacts is done using the WAR algorithm.

Simulations of the catalytic reforming process were performed using the simulator $\mathrm{PRO} / \mathrm{II}^{\circledR}$ of Simulation Sciences Inc. For the simulations, a $20 \%$ recycle of hydrogen was used, and it was assumed that the reactor system is represented by one isothermal reactor, which converts a fixed amount of naphtha, composed of paraffins, five and six membered ring naphthenes and aromatics. The simulations were performed using reactor operating conditions of $540{ }^{\circ} \mathrm{C}$ and $3000 \mathrm{kPa}$. The model of the process assumes a total of 91 reactions for which the kinetics are described in Padmavathi and Chaudhuri [14]. The composition of the reformate from this simulation includes 43 chemical species from $\mathrm{C}_{4}$ to $\mathrm{C}_{9}$, with $24.68 \%$ paraffins, $0.01 \%$ naphthenes and $75.31 \%$ aromatics.

The composition of alkylate described by Simpson et al. [15] includes 17 chemical species from $C_{5}$ to $C_{9}$ alkane isomers. Nagpal et al. [16] list a typical fluidised catalytic cracker (FCC) naphtha fraction. Table 7-20 of the US EPA [17] shows the contribution of each component of the FCC effluent to air emissions. Hamilton [18] gives a typical composition of gasoline 
and components in the olefins group. It was considered for cracked gasoline that there are 48 chemical species from $\mathrm{C}_{5}$ to $\mathrm{C}_{9}$, including $21.6 \%$ paraffins, $6.7 \%$ naphthenes, $54.6 \%$ aromatics and $17.1 \%$ olefins.

\section{Estimation of fugitive emissions and their sources}

Emissions from equipment leaks occur in the form of gases or liquids that escape to the atmosphere through many types of connection points (e.g. flanges, fittings, etc.) or through the moving parts of valves, pumps, compressors, pressure relief devices and certain types of process equipment. In order to determine fugitive emissions losses, the US EPA conducted emission test programs in petroleum refineries, which resulted in a set of average emission factors for process equipment $[17,19]$. These average factors are listed in AP-42 [20] and total losses are estimated by combining the losses for all the pieces of equipment based on their average factors. The Protocol for Equipment Leak Emission Estimates [21] describes the testing procedures, such as screening or bagging (or both), involved in the development of emission factors.

According to Sydney [22] there are several variables that can affect the emission factors such as the fluid phase, pressure, temperature, unit type, equipment size, type of valve, flange, compressor, pump, etc. The use of emission factor methods is based on the assumption that the leak frequency and the equipment emission rates are similar to those of the average process in EPA's studies [23]. Therefore, these methods are most valid for estimating emissions from a process or population of equipment and for a large period of time.

Fugitive emissions of gasoline are influenced by several factors: volatility (measured as Reid vapour pressure), the technology for loading tank trucks and tanks (splash loading, submerged loading, vapour balance, etc.), and storage tank characteristics (colour and design). Methods for estimating emissions from the gasoline marketing system, gasoline trucks in transit, fuel delivery to outlets and storage tank breathing are provided by US EPA [24] and AP-42 [20].

The methodology for estimating emissions in this study is based on average emission factors, combined with information on pumped volume of gasoline blending components produced per year by a refinery. The average emission factors can be estimated based on type, efficiency and extent of emission control measures, applied in distinguished sectors. They incorporate knowledge of specific parameters of the gasoline distribution system and basic physical and chemical parameters of the distributed gasoline.

The average hydrocarbon emission factors used in this study include $1.0 \%$ emissions from (Stage 1) refineries [6], and $0.5 \%$ emissions from (Stage 8 ) marketing terminal and service stations not otherwise considered (which is within the range calculated by the European Environment Agency [5]). The average emission factors for other life cycle stages were taken from the literature [5,17,19-21,24]:

Stage 1: $6.7100 \mathrm{~kg} / \mathrm{m}^{3}$ for the refinery processes of reforming, alkylation and catalytic cracking (combined factor for valves, flanges, pump seals, compressors, other).

Stage 2: $0.2362 \mathrm{~kg} / \mathrm{m}^{3}$ for loading of gasoline in tank trucks and tank cars.

Stage 3: $0.0084 \mathrm{~kg} / \mathrm{m}^{3}$ for transit losses from rail tank cars and trucks.

Stage 4: $0.1922 \mathrm{~kg} / \mathrm{m}^{3}$ for gasoline loading losses from ships and barges.

Stage 5: $0.0065 \mathrm{~kg} / \mathrm{m}^{3}$ for transit losses from ships and barges.

Stage 6: $0.7667 \mathrm{~kg} / \mathrm{m}^{3}$ for emissions from filling underground gasoline storage tanks at service stations.

Stage 7: $0.1200 \mathrm{~kg} / \mathrm{m}^{3}$ for underground tank breathing losses due to the withdrawal of gasoline from the tank.

Stage 8: $3.3550 \mathrm{~kg} / \mathrm{m}^{3}$ for marketing terminal emissions not otherwise considered.

Stage 9: $0.5970 \mathrm{~kg} / \mathrm{m}^{3}$ for motor vehicle refuelling emissions and spillage loss of dispensed gasoline.

The composition of gasoline vapour is highly variable depending on liquid composition as well as on the evaporation process. In order to estimate the mass emission rate from equipment, for a specific VOC in a mixture of several chemicals, the mass fraction of each chemical is multiplied by the mass emission rate of total organic carbon in the equipment $[19,21]$. An assumption of this procedure is that the weight percent of the chemicals in the mixture within the equipment will equal that for the leaking material. In general, this assumption should be accurate for single-phase streams containing any gas/vapour material or liquid mixtures of constituents of similar volatility. Engineering judgment should be used to estimate emissions of individual chemical species from liquid mixtures of constituents with varying volatility or in cases where it is suspected that the leaking vapour has different concentrations than the liquid.

\section{Results, discussion and conclusions}

The potential environmental impacts resulting from the emissions of hydrocarbons to the atmosphere occur in nearly every element of the gasoline production and distribution chain. Generally, after their production, reformate, alkylate and cracked gasoline are blended together in order to formulate the desired gasoline, and 
then the gasoline is loaded into rail cars, barges, coastal tankers, or pipelines, for delivery to market depots or service stations. At service stations, gasoline is transferred into underground storage tanks and subsequently dispensed into vehicle fuel tanks. In this study, the potential environmental impacts of reformate, alkylate and cracked gasoline were evaluated separately, i.e. assuming that the three components are not blended together over all of the life cycle stages. In this way it is possible to assess the relative contribution of each one of the gasoline blending components to the potential environmental impacts, irrespective of the amount of each in a final blend.

\subsection{Potential environmental impact categories}

Eight potential environmental impact categories are available in the WAR algorithm and are used in this analysis. The PEI categories include the following: photochemical ozone creation (or smog) potential (POCP), acidification potential (AP), ozone depletion potential (ODP), global warming potential (GWP), aquatic toxicity potential (ATP), human toxicity potential by exposure (HTPE), human toxicity potential by ingestion (HTPI) and terrestrial toxicity potential (TTP).

The graph of Fig. 1 shows the potential environmental impacts of reformate, alkylate and cracked gasoline over all of the life cycle stages, from refining to distribution and refuelling. The figure shows that photochemical oxidation is the potential environmental impact category with the largest PEI value (assuming an equal weighting of the impact categories). The largest contributions to the photochemical oxidation category come from reformate and cracked gasoline, whereas the contribution of alkylate is almost negligible. Aquatic toxicity (ATP) is the second highest potential environmental impact category, where alkylate is the blending component with the largest contribution, and then cracked gasoline and reformate which also have relatively large PEI values. Terrestrial toxicity (TTP) and human toxicity by ingestion (HTPI) are the next highest potential environmental impact categories, where alkylate is the blending component with the largest contribution followed by cracked gasoline and reformate. Acidification (AP) has important contributions from alkylate and cracked gasoline, whereas the contribution of reformate to acidification is negligible. Human toxicity by exposure (HTPE) has a small contribution from reformate (by comparison with other impact categories), and the contributions of alkylate and cracked gasoline to HTPE are negligible. Global warming and ozone depletion have negligible contributions from the gasoline blending components. To generalize these results, alkylate has the highest PEI values for ATP, TTP and HTPI; reformate and cracked gasoline contribute significantly to the previous three categories and dominate POCP; and alkylate and cracked gasoline have relatively high AP values.

\subsection{Total potential environmental impact}

In order to compare the environmental profiles of the three gasoline blending components, the total PEI was determined by the summation over all (eight) of the potential environmental impact categories as follows:

Total PEI $=\sum_{i=1}^{n} \alpha_{i} \psi_{i}$

where $\sum_{i=1}^{n} \alpha_{i}=1, \quad \alpha_{i}$ is the weighting factor for potential environmental impact category $i$, and $\psi_{i}$ represents the potential environmental impact for category $i$.

Fig. 2 represents the total potential environmental impacts of reformate, alkylate and cracked gasoline, using equal weighting factors for all of the potential environmental impact categories (i.e. the category values

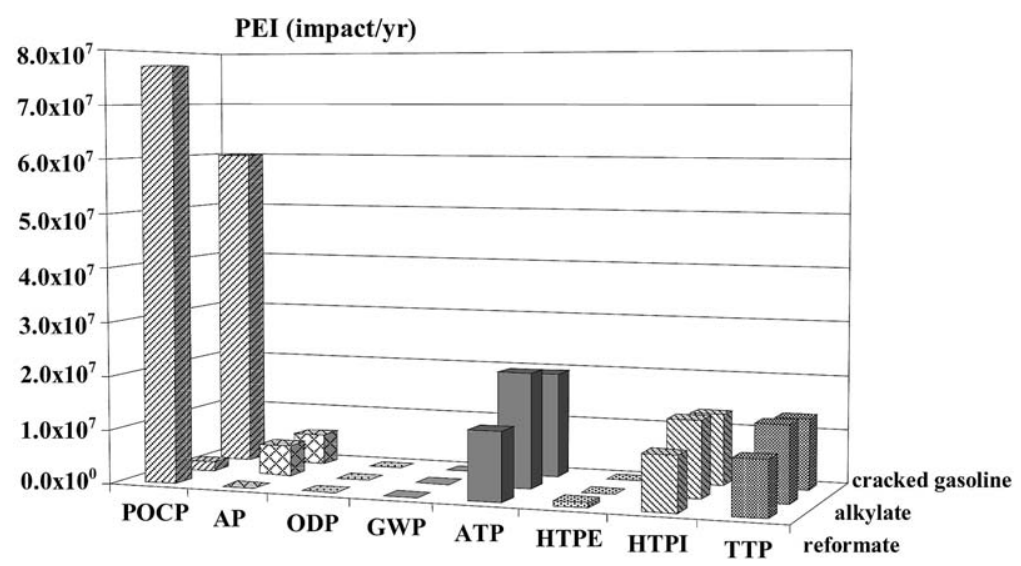

Fig. 1. Potential environmental impacts of reformate, alkylate and cracked gasoline in various impact categories (using equal weighting factors for all of the categories). 
Total PEI (impact/yr)

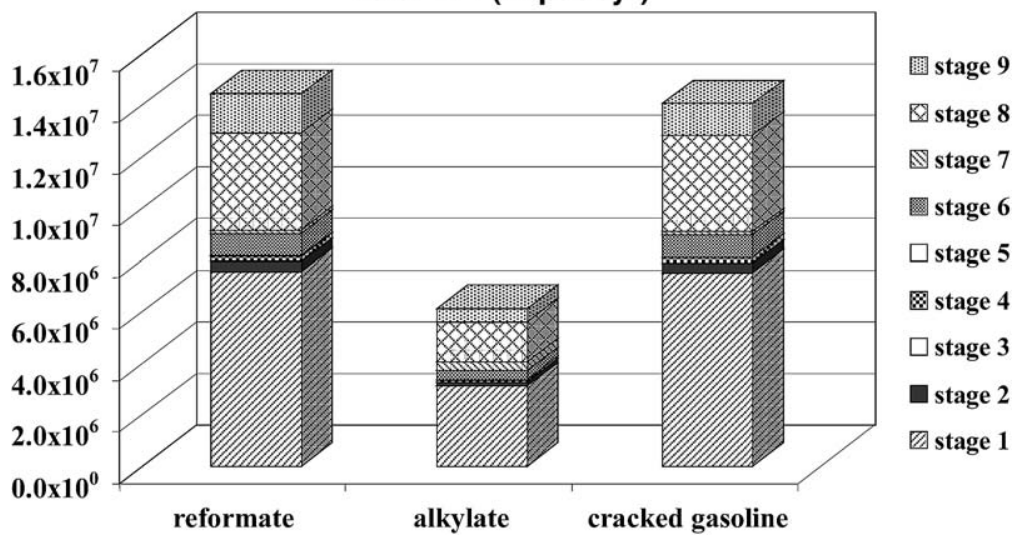

Fig. 2. Total potential environmental impacts of reformate, alkylate and cracked gasoline through the gasoline life cycle (using equal weighting factors for all of the impact categories).

in Fig. 1 have all been multiplied by $\alpha_{i}=0.125$ and summed). From Fig. 2 one can see that reformate and cracked gasoline have much larger total PEI values compared to alkylate. Each bar in Fig. 2 is divided using different patterns, which represent the nine life cycle stages described above. The figure shows that the life cycle stage that contributes the most to the PEI is Stage 1 , referring to the hydrocarbon losses from the refinery processes of reforming, alkylation and catalytic cracking (emissions from equipment items, such as valves, flanges, pump seals, compressors and others). The second largest contribution to the PEI is Stage 8 of the marketing terminal emissions not otherwise considered. Refiners (Stage 1) and marketing terminals (Stage 8) have good manufacturing practices (GMPs), however, particular attention should be focused on a loss prevention approach associated with these two stages. Such GMPs would involve a clear management structure (with well-defined line and advisory responsibilities staffed by competent people), requiring the use of appropriate procedures, codes of practices and standards in the design and operation of a plant. The loss prevention approach should provide for the identification, evaluation and reduction of losses through all steps of a project from research to operation.

\subsection{Sensitivity analysis}

The assessment of the relative importance of the potential environmental impact categories in relation to each other is a value-bound procedure based on their relative environmental harm. Usually, this assessment reflects social values and preferences. For this reason, in order to compare between the different specific potential environmental impact categories and arrive at a further interpretation of the study results, various sets of weighting factors are used, i.e. to perform a sensitivity analysis.

The sensitivity analysis is a quantitative procedure, used to gauge the sensitivity of using different weighting factors on the environmental profile of each gasoline blending component (reformate, alkylate and cracked gasoline). Table 1 shows the nine sets of explicit weighting factor sets (from $\mathrm{WF}_{1}$ to $\mathrm{WF}_{9}$ ) that are used to weight and aggregate the contributions from the different potential environmental impact categories.

Fig. 3 shows the environmental profiles of reformate, alkylate and cracked gasoline obtained from Eq. (1) using the sets of weighting factors from Table 1. This figure shows that depending on the relative importance attributed to each potential environmental impact

Table 1

Various sets of weighting factors for the potential environmental impact categories

\begin{tabular}{|c|c|c|c|c|c|c|c|c|}
\hline Set of weighting factor & TTP & HTPI & HTPE & ATP & GWP & ODP & AP & POCP \\
\hline $\mathrm{WF}_{1}$ & 0.125 & 0.125 & 0.125 & 0.125 & 0.125 & 0.125 & 0.125 & 0.125 \\
\hline $\mathrm{WF}_{2}$ & 0.150 & 0.150 & 0.210 & 0.210 & 0.070 & 0.070 & 0.070 & 0.070 \\
\hline $\mathrm{WF}_{3}$ & 0.105 & 0.105 & 0.300 & 0.210 & 0.070 & 0.070 & 0.070 & 0.070 \\
\hline $\mathrm{WF}_{4}$ & 0.035 & 0.035 & 0.070 & 0.300 & 0.070 & 0.210 & 0.210 & 0.070 \\
\hline $\mathrm{WF}_{5}$ & 0.035 & 0.035 & 0.070 & 0.070 & 0.300 & 0.210 & 0.210 & 0.070 \\
\hline $\mathrm{WF}_{6}$ & 0.035 & 0.035 & 0.070 & 0.070 & 0.070 & 0.300 & 0.210 & 0.210 \\
\hline $\mathrm{WF}_{7}$ & 0.203 & 0.202 & 0.003 & 0.590 & 0.000 & 0.000 & 0.001 & 0.001 \\
\hline $\mathrm{WF}_{8}$ & 0.190 & 0.190 & 0.004 & 0.600 & 0.001 & 0.001 & 0.012 & 0.002 \\
\hline $\mathrm{WF}_{9}$ & 0.150 & 0.140 & 0.006 & 0.700 & 0.001 & 0.001 & 0.001 & 0.001 \\
\hline
\end{tabular}




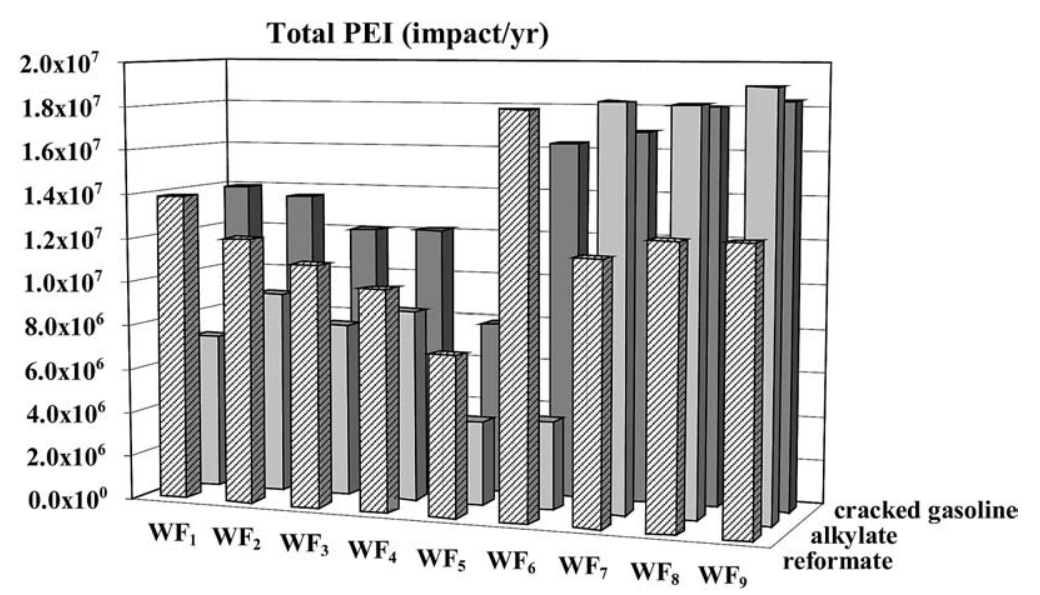

Fig. 3. Total potential environmental impact of reformate, alkylate and cracked gasoline, calculated using various sets of weighting factors for the potential environmental impact categories.

category, the environmental profiles of the three gasoline blending components vary. For example, for the sets from $\mathrm{WF}_{1}$ to $\mathrm{WF}_{6}$, the environmental profiles of reformate and cracked gasoline are larger than that of alkylate. For the sets from $\mathrm{WF}_{7}$ to $\mathrm{WF}_{9}$, the environmental profile of alkylate is worse than those of reformate and cracked gasoline. These sets $\left(\mathrm{WF}_{7}\right.$ to $\mathrm{WF}_{9}$ ) give higher relative weights to aquatic toxicity, terrestrial toxicity and human toxicity by ingestion and lower relative weights in the other five categories.

\section{Acknowledgements}

Teresa Mata would like to thank Fundação para a Ciência e Tecnologia for their support through provision of a postgraduate scholarship.

\section{References}

[1] Directive 94/63/EC of 20 December 1994, on the control of volatile organic compound (VOC) emissions resulting from the storage of petrol and its distribution from terminals to service stations, European Parliament and Council Directive. Official Journal of the European Communities 31.12.1994;L 365:24-33.

[2] Directive $98 / 70 /$ EC of 13 November 1998, relating to the quality of petrol and diesel fuels and amending the Council Directive 93/12/EC, European Parliament and Council Directive. Official Journal of the European Communities 28.12.1998; L 350:58-68.

[3] Directive 2000/71/EC of 7 November 2000, to adapt the measuring methods as laid down in Annexes I, II, III and IV to Directive 98/70/EC to technical progress as foreseen in Article 10 of that Directive, European Parliament and Council Directive. Official Journal of the European Communities 14.11.2000;L 287: $48-50$.

[4] Speight J. Refinery processes, survey. In: 4th ed. Kirk-Othmer encyclopedia of chemical technology, vol. 18 New York: John Wiley \& Sons, Inc; 1996. p. 433-68 18.
[5] Joint EMEP/CORINAIR. Atmospheric emission inventory guidebook. 3rd ed. Copenhagen: European Environment Agency; 2001.

[6] Goyal OP. Reduce HC losses plant-wide: part 1. Hydrocarbon Process 1999;August:97-104.

[7] Siegell JH. Improve VOC emission predictions. Hydrocarbon Process 1997;April:119-21.

[8] Adams WV. Control fugitive emissions from mechanical seals. Chem Eng Prog 1991;August:36-41.

[9] Brandão RF. Monitoring of fugitive emissions in petrochemical plant. Water Sci Technol 1994;29(8):125-33.

[10] Hughes TW, Tierney DR, Khan ZS. Measuring fugitive emissions from petrochemical plants. Chem Eng Prog 1979;August:35-9.

[11] Morgester JJ, Frisk DL, Zimmerman GL, Vincent RC, Jordan $\mathrm{GH}$. Control of fugitive emissions from refinery: valves and flanges. Chem Eng Prog 1979;August:40-5.

[12] Mata TM, Smith RL, Young DM, Costa CAV. Simulation of ecological conscious chemical processes: fugitive emissions versus operating conditions. In: Ribeiro FR, Pinto JJCC, editors. Proceedings of CHEMPOR'01, Aveiro (Portugal), 12-14 September 2001. p. 907-13.

[13] Young DM, Cabezas H. Designing sustainable processes with simulation: the waste reduction (WAR) algorithm. Comp Chem Eng 1999;23:1477-91.

[14] Padmavathi G, Chaudhuri KK. Modelling and simulation of commercial catalytic naphtha reformers. Can J Chem Eng 1997; 75:930-7.

[15] Simpson MF, Wei J, Sundaresan S. Kinetic analysis of isobutane/butene alkylation over ultrastable H-Y zeolite. Ind Eng Chem Res 1996;35:3861-73.

[16] Nagpal JM, Joshi GC, Rastogi SN. Stability of cracked naphthas from thermal and catalytic processes and their additive response. Part I. Evaluation of stability and additive response. Fuel 1995; 74(5):714-9.

[17] US EPA. Assessment of atmospheric emissions from petroleum refining, vol. I. Technical Report EPA-600/2-80-075a. US EPA, Industrial Environmental Research Laboratory; 1980.

[18] Hamilton B. FAQ: automotive gasoline, 1995. Available from: http://www.webpak.net/ marriott/gasoline.htm.

[19] US EPA. Preferred and alternative methods for estimating fugitive emissions from equipment leaks, vol. II. Chapter 4: EPA-454/R-97-004b. Emission Inventory Improvement Program. US EPA, Office of Air Quality Planning and Standards MD-14, Res. Triang. Park; 1996. 
[20] AP-42. Compilation of air pollutant emission factors, vol. I: stationary point and area sources. 5th ed. Office of Air Quality Planning \& Standards, US EPA; 1995.

[21] US EPA. Protocol for equipment leak emission estimates. EPA-453/R-95-017. US EPA, Office of Air and Radiation, Office of Air Quality Planning and Standards, Res. Triang. Park; 1995.
[22] Sydney L. Fugitive emissions. Chem Eng Prog 1989;June:42-7.

[23] Schaich JR. Estimate fugitive emissions from process equipment. Chem Eng Prog 1991;August:31-5.

[24] US EPA. Gasoline marketing (Stage I and Stage II), vol. III. Chapter 11: EPA-454/R-97-004c. Emission Inventory Improvement Program. Office of Air Quality Planning and Standards MD-14, Res. Triang. Park; 1997. 